\title{
THE EFFECT OF USING REHABILITATIVE EXERCISES WITH SUGGESTED TOOLS ON DEVELOPING THE MOTOR RANGE OF THE SHOULDER JOINT IN MARTIAL ARTS PLAYERS
}

\author{
Wissam Qasim Kazim, Asst. Prof. Dr. Wafa Sabah Mohammed \\ University of Baghdad / College of Physical Education and Sports Sciences
}

DOI: $10.37648 / \mathrm{ijrssh.v10i02.033}$

Received: 30 ${ }^{\text {th }}$ March, 2020; Accepted: 20 ${ }^{\text {th }}$ April, 2020; Published: $13^{\text {th }}$ May, 2020

\begin{abstract}
The importance of the research was demonstrated through the preparation of special exercises that carry the possibility of developing the work of ligaments and tendons operating on the shoulder joint, which is reflected in the development of movement in the joint and its dynamic range among players of martial arts for young people with partial rupture of the rounded tendons using some auxiliary tools and the problem of research there is frequent exposure For shoulder joint injuries, especially (rotator cuff rupture) due to the direct friction required by these arts, as well as the dependence of a lot of aids in physical therapy using devices, or their less reliance on rehabilitative exercises using basic aids The researcher used the experimental method on a sample consisting of (7) players. The movement range measurement was used for (7) movements of the shoulder joint and he conducted special rehabilitation exercises for a period of (8) weeks with (3) qualifying units per week. Collecting the results, the researcher reached the conclusions The following: Adoption of exercises for the use of auxiliary tools that work on developing the kinematic range of movements (7) for the round shoulder of martial arts players.
\end{abstract}

\section{INTRODUCTION}

Martial arts is one of the competitive competitive sports with multiple and complex motor skills at the same time, as the large number of correct and effective punches and kicks, with direct friction and different types in the hosts, is one of the main pillars of the game, and one of the most common injuries is the shoulder joint injury, as this has The joint has multiple axes of movement in different directions and wide ranges, and this makes it at the same time more vulnerable to injuries and at a high rate and compared to other joints of the body, and that treatment requires a long time and severe suffering due to the pain facing the person with the shoulder joint, and this All this in exchange for what this joint gives the human body its capabilities to move with great flexibility and wide ranges when performing difficult, complex and important movements in life. These wide ranges put great pressure on the muscles and tendons surrounding the joint, as a muscle or tendon injury running on the shoulder joint affects its motor function, so the normal joint movement stops. 
The importance of the research lies in preparing special exercises that carry the possibility of developing the work of the ligaments and tendons working on the shoulder joint, which is reflected in the development of movement in the joint and its kinetic range among young martial arts players with partial tear of the rounded tendons using some auxiliary tools (rubber ropes, various devices, Stick, resistance, dumbbells). This research contributes to the addition of a new scientific for workers in the field of qualifying players from injuries and returning them to the same previous level before injury and returning to the stadiums with high physical fitness.

\section{Research Problem}

Through the experience of the researcher, being a former player and currently trained in a martial arts, he noticed that there is a high exposure to shoulder joint injuries, especially (Rotator cuff tear) due to the direct friction required by these arts, in addition to adopting a lot of aids in physical therapy using devices, Or the lack of reliance on rehabilitative exercises by using basic aids designed to examine the affected limb, which are essential factors in speeding up the rehabilitation process. Therefore, the researcher considered the use of special exercises according to some tools to rehabilitate the muscles working on the shoulder joint after he was torn Shanbezehi tendons of the shoulder rotator of the players martial arts for young people.

Research objectives

- Prepare special exercises using auxiliary tools to rehabilitate the muscles working on the shoulder joint after suffering partial tear of the rotator cuff tendons of young martial arts players.

- Knowing the effect of special exercises on the motor range of the shoulder joint.

: Research hypothesis

There were statistically significant differences between the results of the pre and post tests in the motor range of the shoulder joint.

\section{Research Areas}

The human sphere: a sample of young martial arts players with partial tear of (7) rounded hamstrings.

.Time domain: for the period from 14/11/2019 to $13 / 1 / 2020$

Spatial domain: Adhamiya Sports Club.

\section{MATERIALS AND METHODS:}

\section{Research Methodology:}

The researcher used the experimental method, which is, "It is the only method that can truly test the hypotheses of the relationships of cause or effect." (3:217) As the most important characteristic of accurate scientific activity and the researcher's use of the experiment method is to design a single experimental group.

\section{Search community and sample:}

The research community was chosen intentionally by the injured players in the shoulder joint, especially the partial tear injury of the rotator cuff tendons of the martial arts players, the number of (11) samples from the injured method in the joint, and the selection of a sample of them randomly, the number (7) players, by lot After specifying several conditions with the members of the experimental group, they were approved.

Conditions for selecting a sample

The members of the sample must have partial tear tendons of the rotator cuff -

To be a martial arts athlete -

- That the individuals of the sample have a serious desire to participate in the qualifying curriculum.

.That he is not subject to any other method -

- Regularity in the application of the qualifying curriculum for the duration of the experiment conducted under the supervision of the researcher in Adhamiya Club.

.- To answer family history medical questions and write a commitment to agree to conduct the experiment

.Be subjected to clinical examination and $\mathrm{x}$-ray, and if possible, MRI - 
Figure (1)

The MRI test shows individuals of the sample

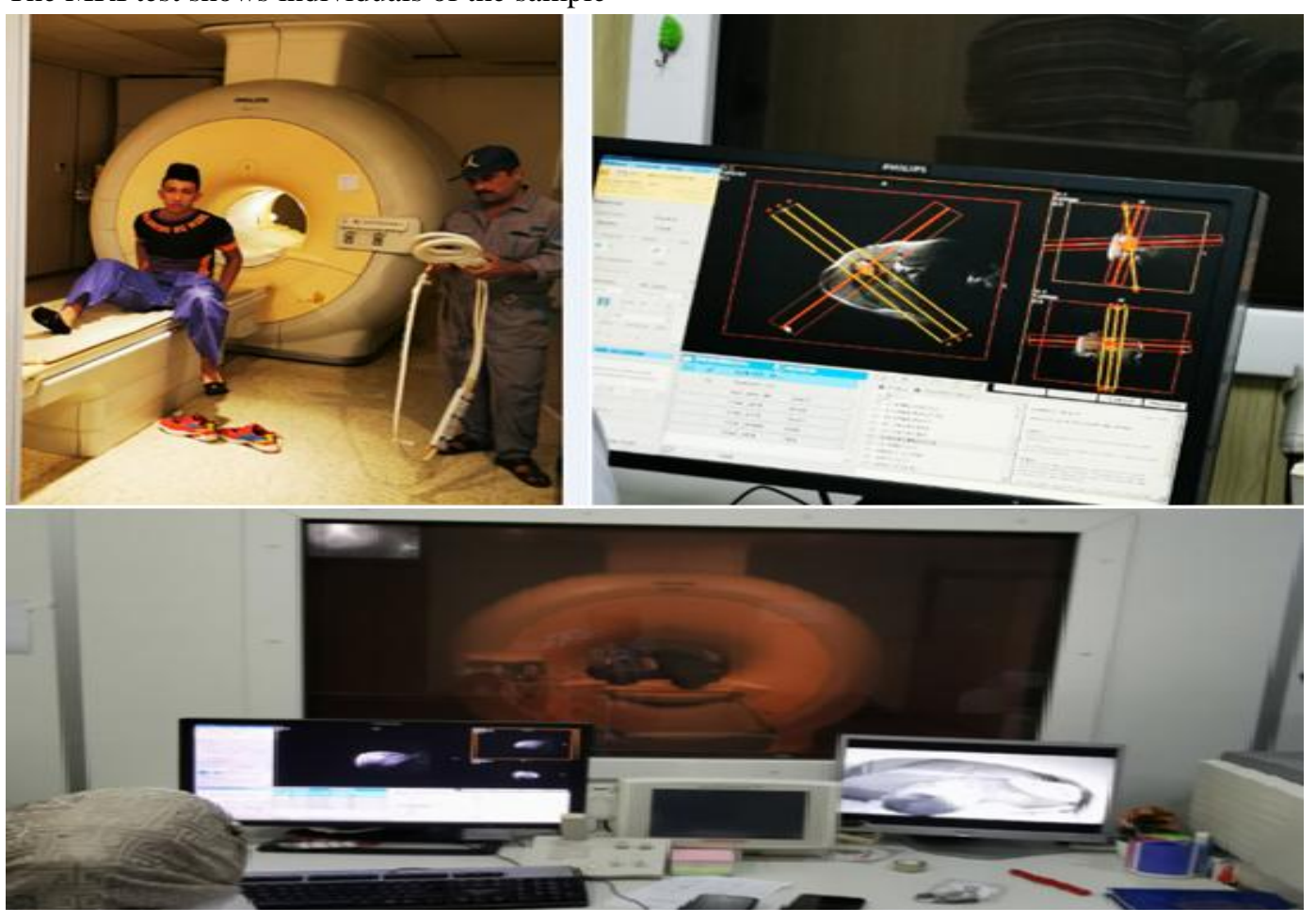

To achieve full homogeneity, the researcher will adopt the foundations for injury, as follows:

- Homogeneity in the degree of injury: all individuals in the research sample who have partial rupture of the tendons of the rotator cuff.

- Homogeneity at the site of the injury: All members of the sample who have tendons of the shoulder joint with medical supervision.

Homogeneity with measurements

Table (1)

Homogeneity is shown by the search variables

\begin{tabular}{|l|l|l|l|l|l|}
\hline skewness & $\begin{array}{l}\text { standard } \\
\text { deviation }\end{array}$ & Mediator & the middle & $\begin{array}{l}\text { measruing } \\
\text { unit }\end{array}$ & variable \\
\hline 0.519 & 4.151 & 104 & 104.28 & Degree & Shoulder bend \\
\hline 0.00 & 2.160 & 36 & 36 & Degree & Stretch the shoulder \\
\hline 1.367 & 3.545 & 98 & 99.285 & Degree & Shoulder off \\
\hline 0.285 & 2.811 & 64 & 64.285 & Degree & Shoulder horizontal shoulder \\
\hline 0.818 & 3.047 & 23 & 23.571 & Degree & Horizontal shoulder rounded \\
\hline 0.051 & 1.889 & 34 & 33.714 & Degree & Shoulder inner rotation \\
\hline 0.074 & 2.429 & 60 & 59.714 & Degree & External shoulder rotation \\
\hline
\end{tabular}

It is noted in the above table that the convolution values were limited between (+3 and _ 3 ), and this indicates the homogeneity of the research sample in all study variables. 
Means of gathering information, tools and devices used in research:

Means of information gathering

. Arab and foreign sources -

. Personal interviews -

. The opinions of experts and specialists -

. - Measurement and news

Devices and tools used

- A factory for performing exercises

A dynamometer for measuring the American-made muscle strength -

A Japanese-made device for measuring the elasticity of the shoulder joint -

Casio Camera -

Medical scale -

tape measure -

Dumblets with different weights -

Iron bar -

Special flexibility stick -

rubber ropes -

Different weights -

Mastaba -

a chair -

Rubber balls -

Field research procedures:

Determine the measurements used in the research

Measurements of the kinetic range of the rounded cuff The measurement of the kinematic range of the shoulder joint was performed in (7) different movements:
Shoulder bending movement:

The laboratory sits with its arm at the side of the body and down -

- The arms of the goniometer are placed on the acromial protrusion of the shoulder blade and on the lateral side of the arm -

The laboratory raises its arm forward, upward and at the sagittal level -

The fixed arm of the goniometer is parallel to the trunk -

The moving arm of the gyrometer is parallel to the humerus -

You read and record the achieved angle between the two arms of the jumper -

-The ideal kinetic range for the movement of the shoulder fold is (0-170) degrees (6: 221).

:Shoulder stretch movement

The lab will be visible, with the arm at the side of the body and down -

The arms of the goniometer are placed on the acromial protrusion of the shoulder blade and on the lateral side of the arm -

The laboratory moves its arm back, up and at the sagittal level -

The fixed arm of the goniometer is parallel to the trunk The moving arm of the gyrometer is parallel to the humerus -

You read and record the achieved angle between the two arms of the jumper -

The ideal kinetic range of the shoulder flexion movement is (0-60) degrees-

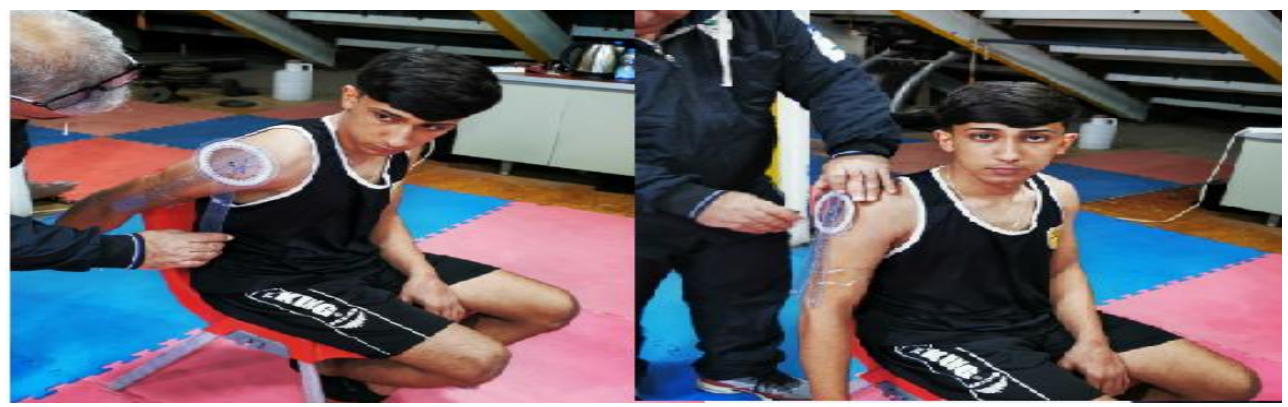

Figure (3)

The range of motion illustrates the length of the shoulder

Shoulder retract movement

The laboratory sits with its arm at the side of the body and down - 
-The arms of the goniometer are placed on the acromial bump of the shoulder blade and on the back of the shoulder The laboratory raises its arm to the side, up and at the coronary level -

The fixed arm of the goniometer is parallel to the trunk -

The moving arm of the gyrometer is parallel to the humerus -

You read and record the achieved angle between the two arms of the jumper The ideal kinetic range of the shoulder flexion movement is (0-170) degrees -

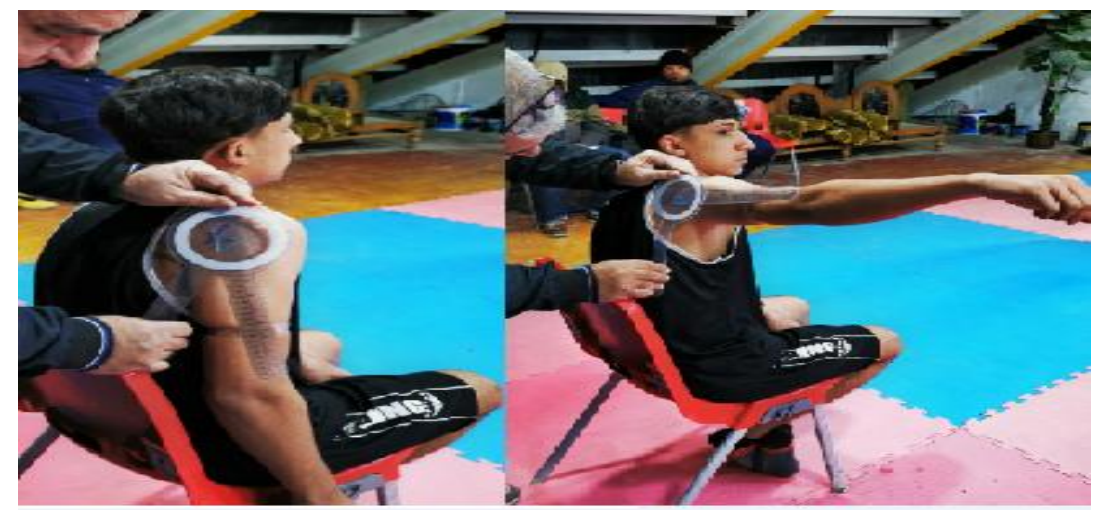

Figure (4)

The range of motion demonstrates the shoulder's distance

shoulder horizontal shoulder movement

The laboratory sits with the arm bent at a 90-degree angle from the shoulder joint so that the palm of its hand is lower and its arm parallel to the ground.

The arms of the goniometer are placed on the acromial bump of the shoulder blade.

- The laboratory moves his arm away from the fair line of the body and on the transverse plane.

The fixed arm of the goniometer is parallel to the top of the shoulder -

The moving arm of the gyrometer is parallel to the humerus -

You read and record the achieved angle between the two arms of the jumper -

- The ideal kinetic range of the shoulder flexion movement is (0-90) degrees

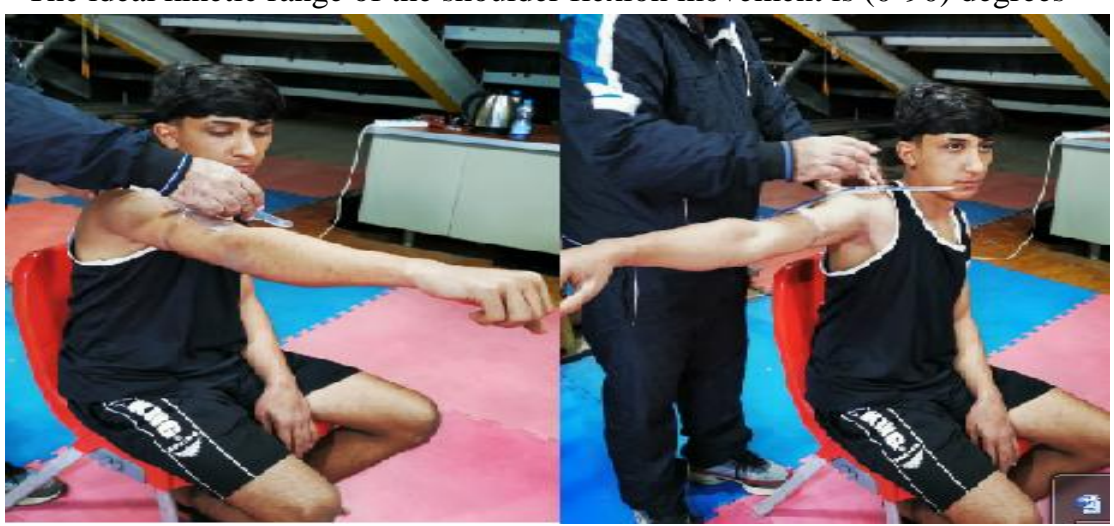

Figure (5)

The range of motion measure the horizontal shoulder distance

horizontal shoulder movement

- The laboratory sits with the arm bent at a 90-degree angle from the shoulder joint so that the palm of its hand is lower and its arm parallel to the ground.

- The arms of the goniometer are placed on the acromial bump of the shoulder blade. 
- The laboratory moves its arm inwards, approaching the fair line of the body and on the transverse plane.

The fixed arm of the goniometer is parallel to the top of the shoulder -

The moving arm of the gyrometer is parallel to the humerus -

You read and record the achieved angle between the two arms of the jumper -

The ideal kinetic range of movement of the shoulder fold is $(0-45)$ degrees -
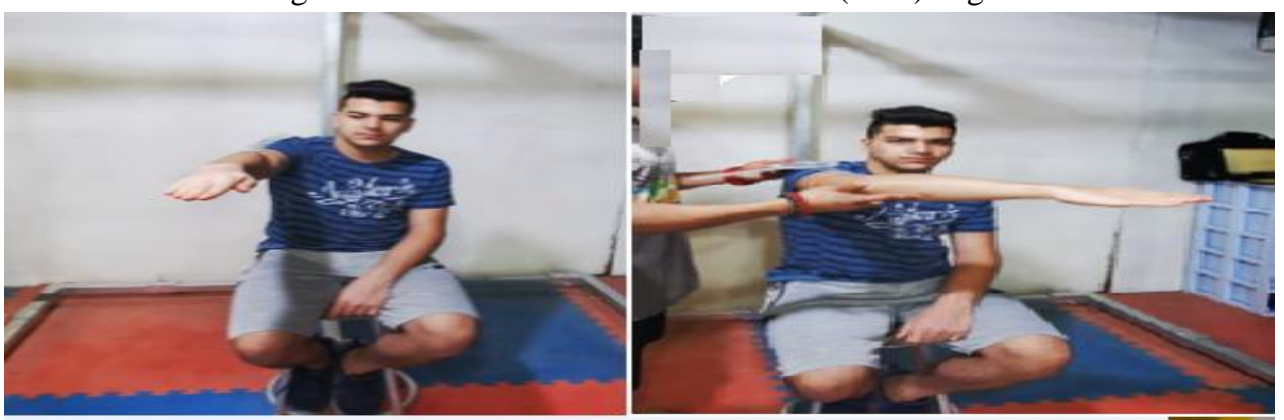

Figure (6)

The range of motion measure the horizontal shoulder approximation

shoulder inner rotation movement

- The laboratory sits with the position of the humerus rounded from the trunk, so that the elbow joint is at an angle of (90) degrees, and the humerus must be in the center perpendicular to the body.

The arms of the goniometer are placed on the elbows of the shoulder joint -

The laboratory moves the humerus inward toward the just line of the body -

The fixed arm of the gonometer is parallel to the humerus -

The moving arm of the gyrometer is parallel to the radius bone -

You read and record the achieved angle between the two arms of the jumper -

The ideal kinetic range of the shoulder flexion movement is (0-60) degrees -

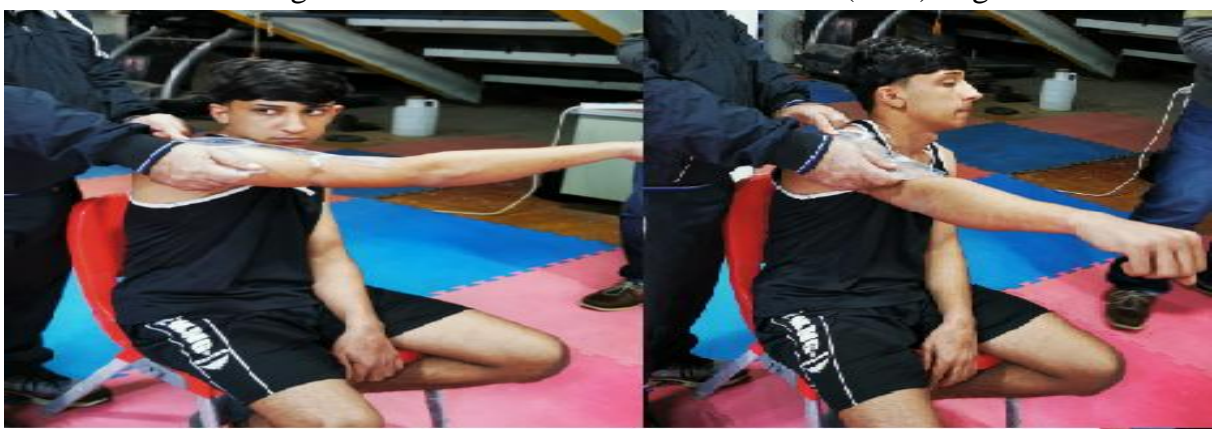

Figure (7)

The range of motion shows the internal rotation of the shoulder

Shoulder rotation movement

- The laboratory sits with the position of the humerus rounded from the trunk, so that the elbow joint is at an angle of (90) degrees, and the humerus must be in the center perpendicular to the body -

The arms of the goniometer are placed on the elbows of the shoulder joint -

The laboratory moves the humerus out of the body's fair line -

The fixed arm of the gonometer is parallel to the humerus -

The moving arm of the gyrometer is parallel to the radius bone -

You read and record the achieved angle between the two arms of the jumper -

The ideal kinetic range of movement of the shoulder fold is (0-80) degrees - 


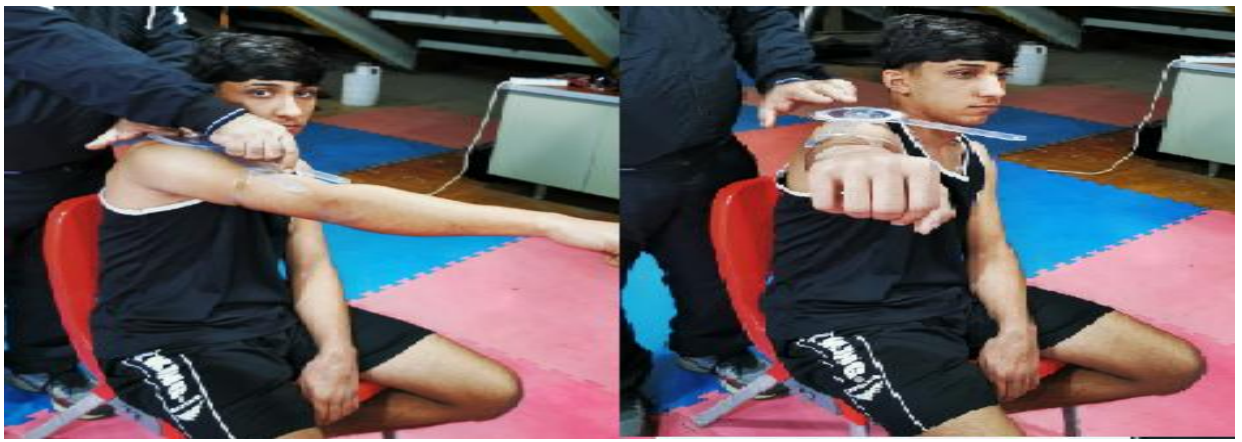

Figure (8)

Measure the range of motion of the outer shoulder rotation

\section{Exploration Experience}

The researcher conducted the reconnaissance experiment on the poll sample, which consists of (4) players, on Thursday, 11/14/2019 at four in the afternoon. For the purpose of carrying out exercises on the auxiliary tools and their purpose is to identify the way to conduct the tests and train the auxiliary team to supervise them, as well as the time required to perform each test.

.Know the time taken to implement the vocabulary of the curriculum -

- Identify errors that occur during the implementation of the vocabulary of the curriculum and overcome them, and identify difficulties while performing assistive tools. Identify the break times between attempts when implementing the qualifying curriculum procedures.

Identify the stresses and repetitions of each exercise.

\section{Main experience}

tests before

On Saturday, November 16, 2019, at 4:00 p.m., the researcher made measurements of the kinetic range of the research group to test the range according to the required conditions.

(Bending of the shoulder, then extending the shoulder, shoulder distancing, shoulder approximation, horizontal shoulder distancing, horizontal shoulder rotation, inner shoulder rotation, and outer shoulder rotation)

Qualification Method Using Utilities

The researcher has prepared special training exercises based on some scientific sources and after taking the opinions of some experts and specialists in the field of physical education, physical therapy and sports medicine in order to choose the best and most suitable rehabilitation exercises that guarantee the return of the partial rupture of the rotated cuff of the shoulder joint to the martial arts players in the shortest possible time and vocabulary was applied Rehabilitation exercises for the period from Monday 18/11/2019 until Monday $13 / 1 / 2020$ for a period of (8) weeks, with (3) rehabilitative units per week, and the unit time was (3040) minutes.

Exercises using aids also included a wrist device (rubber ropes, various dumbbells, a stick, rubber balls, and various devices, resistance)

- The researcher adopted determining the maximum strength of the affected arm for each member of the experimental group

- Gradient principle by doing exercises from easy to hard. The qualification program was formulated based on the data

- The first week included exercises without tools with lying down and standing and sitting

- The second week is exercises using the stick, the third week is exercises using the rubber balls

The fourth week, exercises using rubber cords -

- The fifth, sixth, seventh and eighth week Exercises using different resistances and different devices

- The researcher used two methods to develop muscle strength, namely fixed training and mobile training Strength exercises are followed by fixed stretching exercises -

- Movement is limited to the shoulder joint in specific directions (dimensions, rounding, lifting, lowering and pulling over the shoulder and inward and outward to perform rotational motion)

- These exercises were divided into six exercises in each rehab unit, which represents an exercise for each muscle 
group of the peripheral muscles of the shoulder, provided that the exercises group for the fixed training in one day and the exercises for the mobile training on another day.

Tests After

After the end of the period of applying the rehabilitative exercises, the researcher conducted the post-test on Thursday, 1/16/2020, four o'clock in the afternoon.

\section{Statistical means}

The researcher used the appropriate statistical means that serve the research through the statistical system spss and includes the following means (arithmetic mean, median and standard deviation. And test $(\mathrm{t})$ for non-independent samples).

\section{RESULT AND DISCUSSION:}

View and analyze the results of the measurements of the kinetic range (tribal and dimensional) of the experimental group and discuss them

Table (2) shows the mean, standard deviations and value (T) of the experimental group in the research that were used in the pre and post measurements.

Table (2)

Arithmetic mean, standard deviations and $(\mathrm{T})$ value of the search sample

\begin{tabular}{|c|c|c|c|c|c|c|c|c|c|c|}
\hline \multirow[t]{2}{*}{ indication } & \multirow{2}{*}{$\begin{array}{l}\text { mistake } \\
\text { percentage }\end{array}$} & \multirow{2}{*}{$\begin{array}{l}\text { Calculated } \\
\text { value }(\mathrm{t})\end{array}$} & \multirow[t]{2}{*}{$\mathrm{PF}$} & \multirow[t]{2}{*}{ F. } & \multicolumn{2}{|l|}{ distance } & \multicolumn{2}{|l|}{ Before } & \multirow{2}{*}{$\begin{array}{l}\text { measur } \\
\text { ing unit }\end{array}$} & \multirow[t]{2}{*}{ variable } \\
\hline & & & & & $\begin{array}{l}\text { standard } \\
\text { deviation }\end{array}$ & $\begin{array}{l}\text { Arithmetic } \\
\text { mean }\end{array}$ & $\begin{array}{l}\text { standard } \\
\text { deviation }\end{array}$ & $\begin{array}{l}\text { Arithmetic } \\
\text { mean }\end{array}$ & & \\
\hline moral & 0.000 & 9.383 & 5.437 & 19.285 & 4.859 & 123.571 & 4.151 & 104.285 & Degree & $\begin{array}{c}\text { Shoulde } \\
\mathrm{r} \text { bend }\end{array}$ \\
\hline moral & 0.000 & 7.839 & 2.5071 & 7.4285 & 1.511 & 43.428 & 2.160 & 36.0 & Degree & $\begin{array}{c}\text { Stretch } \\
\text { the } \\
\text { shoulder }\end{array}$ \\
\hline moral & 0.020 & 3.147 & 4.203 & 5.000 & 3.039 & 104.285 & 3.545 & 99.285 & Degree & $\begin{array}{c}\text { Shoulde } \\
\text { r off }\end{array}$ \\
\hline moral & 0.000 & 17.329 & 2.115 & 13.857 & 2.410 & 78.142 & 2.811 & 64.285 & Degree & $\begin{array}{l}\text { Shoulde } \\
\mathrm{r} \\
\text { horizont } \\
\text { al } \\
\text { shoulder }\end{array}$ \\
\hline moral & 0.000 & 9.750 & 1.5118 & 5.571 & 2.794 & 29.142 & 3.047 & 23.571 & Degree & $\begin{array}{l}\text { Horizon } \\
\text { tal } \\
\text { rounded } \\
\text { shoulder }\end{array}$ \\
\hline moral & 0.000 & 8.148 & 1.3451 & 4.142 & 2.340 & 63.857 & 2.429 & 59.714 & Degree & $\begin{array}{c}\text { External } \\
\text { rotate of } \\
\text { the } \\
\text { shoulder }\end{array}$ \\
\hline moral & 0.000 & 11.456 & 2.309 & 10.00 & 1.799 & 43.714 & 1.889 & 33.714 & Degree & $\begin{array}{c}\text { Shoulde } \\
\text { r inner } \\
\text { rotation }\end{array}$ \\
\hline
\end{tabular}


Discuss the results of the differences between the tribal and posterior measurements of the kinetic extent of the muscles operating on the shoulder joint of the experimental group:

From the table on measurements of the kinetic extent of the muscles working on the shoulder joint, significant differences are observed between the results of the pre and post tests in all kinetic range variables. The researcher attributes the improvement in the range of motion of the various shoulder movements to the effectiveness of the exercises used using auxiliary tools in rehabilitating the muscles working on the shoulder joint after their injury. The result of using the gradient to the point of connection to a degree of pain at first and uses the range of motion without resistance and using the tapes Weak elasticity ie low tension (weak resistance) with muscle lengthening as far as possible without the appearance of pain to avoid duplication of injury as a result of pulling tendons or working muscles as these exercises were adopted on the principles and principles of sports training by organizing them for periods of time $\mathrm{m}$ Relative to the stage of rehabilitation to reach the stage of complete recovery, that is, organizing the work of stresses, rest and repetition, and the return of the work of the joint to the nature of his work, as "organized training results in an increase in the individual's ability as a result of performing physical exercises for several days, weeks, or months, by normalizing the body's systems of performance The optimal for these exercises, in other words, the effect of physical exercises stimulates the muscle cells for normalization, and that they are more economical in performing the intensity of pregnancy "(5: 8) and the effect of the duration of the rehabilitation program on the level of the motor range of the shoulder, and this is what (Mativiv) emphasized" that the growth of flexibility It is achieved in more than ten units Training, that is, it is sufficient for its integration to use (8-10) weeks in order to reach the important part of the possibility of developing the kinetic capacity that relates to improving muscle stretching. "(2: 242) In addition to this, the use of various auxiliary tools and new exercises and a change in their proportions, shapes and arrangement And the method of its implementation which helped to raise the level of the motor range of the joint and this is consistent with what was indicated by (Yassin Taha and Wadih Yassin, 1986). "Getting enough flexibility for specific muscles, ligaments, and tendons of a joint or a group of joints in a particular movement or activity depends on the amount of And the intensity of the exercises that lead in a wide range of movement as well as the degree of flexibility Almak Cause for the individual " (4:24), which helped in obtaining the neuromuscular adaptation by alleviating the degree of pain and functional adjustment working to the maximum extent of the joint because of these matters, and this is confirmed by (Hussein Ali Al-Ali and Amer Fakher 2010)" that these changes in exercises within the training dose contribute In training the muscles in different physiological conditions, they undoubtedly add a new kind of physiological effect to their different condition when performing the exercise in various and regular methods. (1: 196) Therefore, it is evident that there is an improvement in the kinetic range of the experimental group due to the exposure of its members to the rehabilitation program Prepared by the researcher.

\section{CONCLUSIONS:}

- Adopting exercises for using auxiliary tools that develop in the kinetic range of the shoulder fold movement for martial arts players.

- The adoption of exercises for the use of auxiliary tools that work on developing the kinetic range of the shoulder stretch movement of martial arts players.

- Adopting exercises for using auxiliary tools that develop in the kinetic range of the shoulder-distancing movement of martial arts players.

- Adopting exercises for using auxiliary tools that develop in the kinetic range of the movement of horizontal shoulder blades for martial arts players.

- Adopting exercises for using auxiliary tools that develop in the kinetic range of the movement of horizontal shoulder blades for martial arts players.

- Adopting exercises for using auxiliary tools that develop in the kinetic range of the external shoulder rotation movement for martial arts players.

- The adoption of exercises for the use of auxiliary tools that work on developing the kinematic range of the movement of the internal rotation of the shoulder among martial arts players.

\section{ENDORSEMENT:}

- Adoption of exercises for the use of auxiliary tools for the rehabilitation of shoulder injuries among members of the research sample. 
- Holding training sessions to introduce the method of qualification by using exercises for using therapists aids.
- Carrying out other studies and on both sexes for the various games to get acquainted with the effect of specific exercise exercises using auxiliary tools.

\section{REFERENCES:}

- Hussein Ali Al-Ali, Amer Fakher Shaghati: Strategies of Methods and Techniques of Athletic Training, First Edition: (Baghdad, Al-Nur Press, 2010)

- Mativiv, (translation) Qasim Hassan Hussein: Rules for Athletic Training: (Mosul, Mosul University Press, 1988)

- Muhammad Hassan Allawi and Osama Kamel Ratib. Scientific Research in Physical Education and Psychology, Cairo, Arab House of Thought, 1999.

- Yassin Taha and Wadih Yassin: Physical preparation for women: (University of Mosul, Dar Al-Kutub for Printing and Publishing, 1986)

- Edington,D.W.and Edugertion, V.R:The Biology of Physical.Activity ,Boston, Houghton Mifflin Vompany.

- Klaus Buckup, Clinical tests for the musculoskeletal system, Germany, Georg Thieme Verlag, 2004. 